DOI: 10.2507/31st.daaam.proceedings.084

\title{
Validation of Process Stability IN THE AVIATION INDUSTRY
}

\author{
Nikola Skřivanová \& Martin Melichar
}
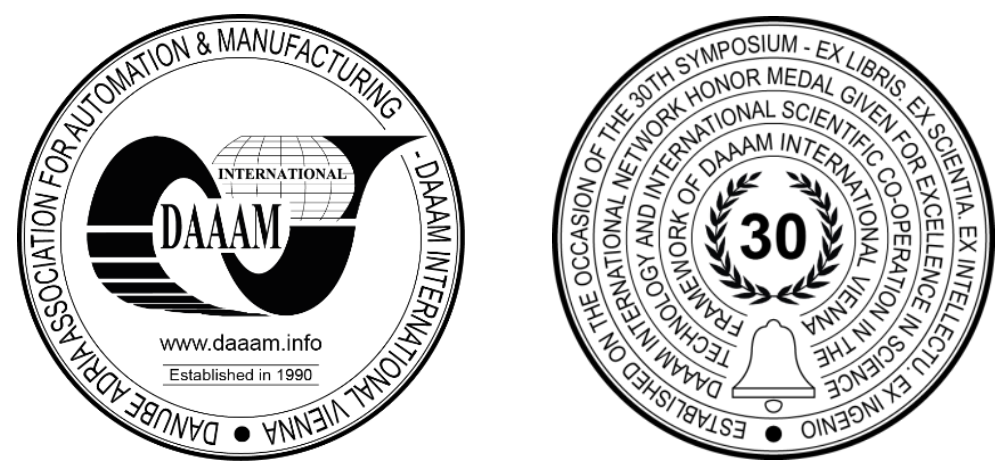

This Publication has to be referred as: Skrivanova, N[ikola] \& Melichar, M[artin] (2020). Validation of Process Stability in the Aviation Industry, Proceedings of the 31st DAAAM International Symposium, pp.0614-0618, B. Katalinic (Ed.), Published by DAAAM International, ISBN 978-3-902734-29-7, ISSN 1726-9679, Vienna, Austria DOI: $10.2507 / 31$ st.daaam.proceedings.084

\begin{abstract}
The article deals with the validation of the stability of the process of inspecting aircraft components in the aviation industry. During the experiment, the X-ray and CT control system SCIOX Cabinet was used, which allows nondestructive testing in the form of CT models. The experiment was used to inspect a structure that is used as the core for the shape of cells in sandwich composites - a honeycomb. As part of the deployment of this non-destructive method, stabilization of the process was achieved with an increase in the degree of credibility of the process, given that the validated pieces are not destroyed, but can continue onwards to the customer, which was the goal of this experiment.
\end{abstract}

Keywords: CT model; X-ray; validation; non-destructive method

\section{Introduction}

The busiest mode of transport today is air transport. It has no competition in the world in terms of speed and distance travelled. Due to the fact that more and more passengers are using this service and an even greater increase is expected in the future, the issue of the production of aircraft components is increasingly topical. In the aviation industry, the Czech Republic today is an important link in the supply chain. For large companies, the industry in the Czech Republic is attractive due to its ability to develop components and integrate them into various types of aircraft. Complex parts are produced from aluminium alloys, steel, titanium and composite materials, which are used in various parts of aircraft.

The future of the aviation industry is dynamic and presents many opportunities and threats. The private, commercial and air freight segments are experiencing strong long-term growth rates, but are also confronted with short-term volatility and shocks due to an increasingly complex and dynamic environment. Further liberalization and deregulation, more intense competition, changing customer requirements and a lack of resources are just some of the factors contributing to the growing demands on aircraft component suppliers and their uncertain future in the supply market. Aviation is also affected by the fact that it is one of the most highly regulated sectors. There are many regulations and certifications that companies must comply with. The aviation industry is extremely demanding on safety. All systems must not only be reliable, but also have multiple levels of safety. This creates enormous demands on the details of all the designs, precise processing of technical documentation and, above all, emphasis on the final inspection of all parts and validation of manufactured pieces. 
It is these demands for quality, safety and the resulting strict control of manufactured pieces that are an increasingly topical issue in today's market for aircraft components. Stabilization of the validation process of manufactured pieces increases the credibility of the production process in the eyes of the customer and thus increases the competitiveness of the manufacturer. Therefore stabilizing this process is beneficial for all parties.

A separate section in the field of aviation comprises the so-called 'special processes'. These special processes are characterized by the fact that we cannot unambiguously control the result. This means that these special processes must be validated under controlled conditions, and it is not possible to determine whether the product is OK or NOK without destroying the output of this special process. As part of our experiment, new knowledge in the field of non-destructive testing is applied to the special process of bonding sandwich composites in order to stabilize and improve it. We deal with the problem of demanding testing, when a sandwich composite with a honeycomb core is inspected, and there is large distortion of the results. This special process is currently only checked and validated by destructive methods. In the case of inspection of sandwich composites with honeycomb cores, conventional inspection involves the destruction of the material and subsequent visual inspection of the core and coating. The amount/layer of adhesive connecting the core to the coating is checked. We investigate the possibility of using an X-ray machine in order to improve the validation of the special inspection process and thus increase the degree of credibility of the entire special process. We investigated whether this non-destructive technology, with the irradiation of the entire material, makes it possible to record the layer of adhesive connecting the core to the coating. [1], [2], [3]

A separate section in the field of aviation comprises the so-called 'special processes'. These special processes are characterized by the fact that we cannot unambiguously control the result. This means that these special processes must be validated under controlled conditions, and it is not possible to determine whether the product is OK or NOK without destroying the output of this special process. As part of our experiment, new knowledge in the field of non-destructive testing is applied to the special process of bonding sandwich composites in order to stabilize and improve it. We deal with the problem of demanding testing, when a sandwich composite with a honeycomb core is inspected, and there is large distortion of the results. This special process is currently only checked and validated by destructive methods. In the case of inspection of sandwich composites with honeycomb cores, conventional inspection involves the destruction of the material and subsequent visual inspection of the core and coating. The amount/layer of adhesive connecting the core to the coating is checked. We investigate the possibility of using an X-ray machine in order to improve the validation of the special inspection process and thus increase the degree of credibility of the entire special process. We investigated whether this non-destructive technology, with the irradiation of the entire material, makes it possible to record the layer of adhesive connecting the core to the coating. [3], [4], [5]

\section{Experiment description}

We experimentally investigated a sandwich composite used in the aerospace industry. Sandwich materials are an advanced type of composite and we classify them as layered materials. The construction (sandwich) consists of several layers with different properties, which are firmly connected to each other and form an inseparable whole. The principle of an effective sandwich construction consists in covering the core on both sides with thin outer layers of solid material, called 'coatings'. The filling material between the coatings is the 'core' of the sandwich, which is characterized mainly by its low weight and good mechanical properties in compression and shear. For the outer layers, which perform the function of protecting the core, the key properties are different, because they are most stressed by bending (pressure and tension). These parts are mostly connected to each other by a layer of glue. For a better idea of this layered construction, see Figure 1, which shows a sandwich composite with a honeycomb core. [6], [7]

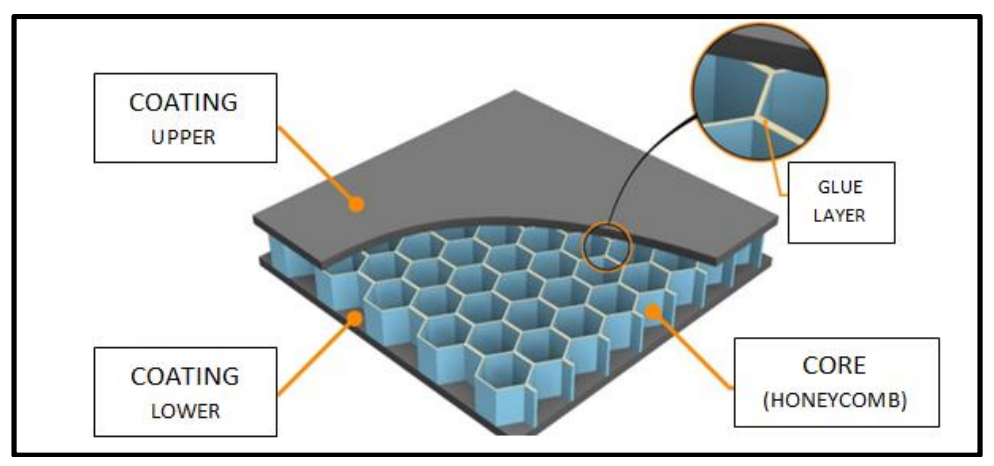

Fig. 1. Description of sandwich material

The aim of the experiment is to improve the validation of the special process of the gluing of sandwich composites without destructive intervention. The X-ray and CT control system SCIOX Cabinet was used in the experiment, see Fig. 2. X-ray and CT irradiation equipment are reliable devices that allow the detection of defects located below the surface of the tested part. All our tests were performed under controlled conditions at a temperature of $20 \pm 1{ }^{\circ} \mathrm{C}$ and a humidity of $45 \pm 1 \%$. [8] 


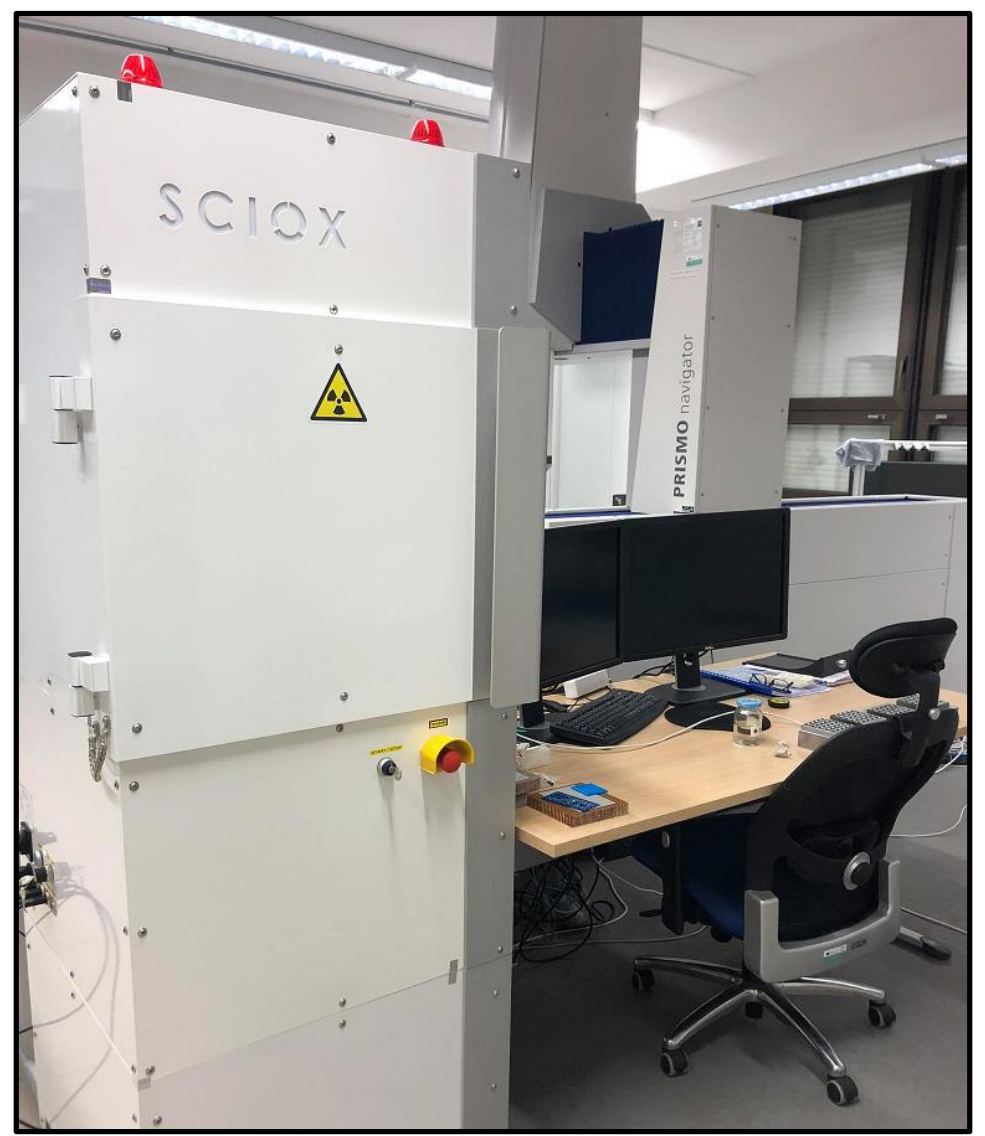

Fig. 2. SCIOX Cabinet

The material was supplied by the manufacturer in the form of sheets, which were used as test samples, see Fig. 3 . The manufacturer performed a conventional inspection of these boards by cutting them and conducting a visual inspection of the adhesive layer. The output of this check was the verdict of either NOK or OK in the inspected section. A drawback is that this test is related only to the inspected section and not to the entire area of the sandwich composite.

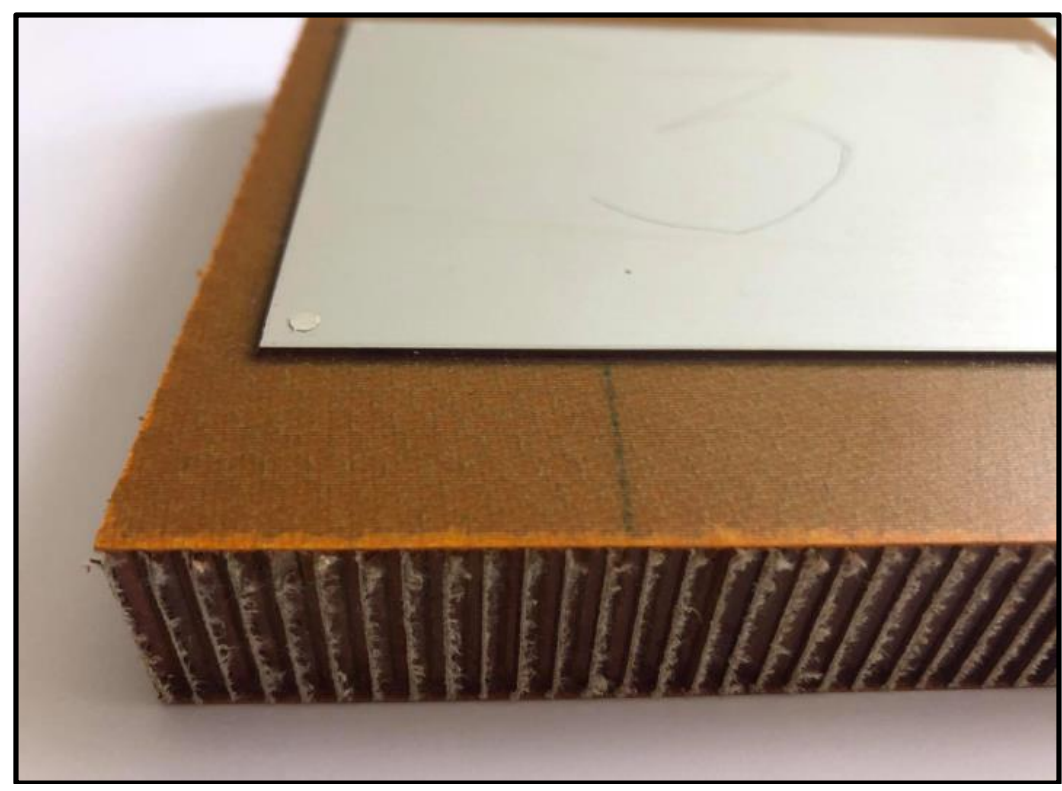

Fig. 3. Test sample

The CT model, see Figure 4, and its examination in various sections, gave positive results. Primarily, this technology gives a complete visualization of the structure and provides the certainty that the material is in order without internal defects or damage, which is very valuable information. 


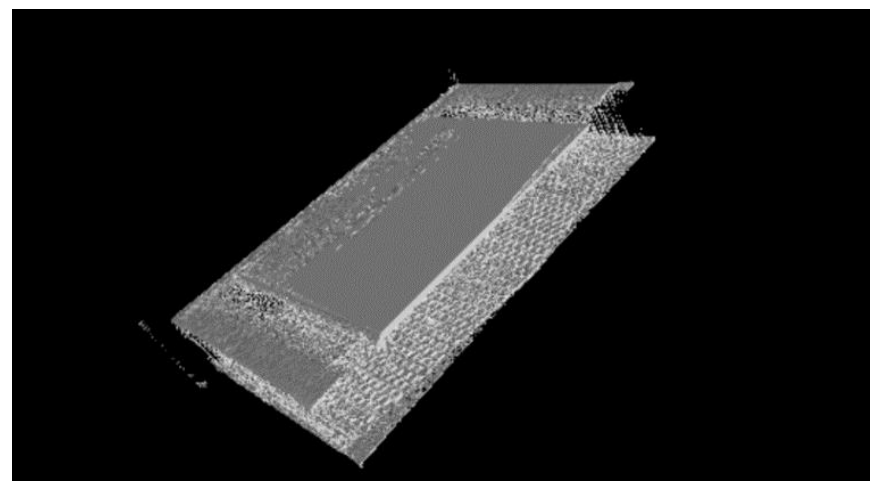

Fig. 4. CT model of test sample

Secondly, in the sections of the CT model it is possible to see the layers of glue used to join the coating and the core, which was the main reason for the research. The question is whether this technology would not be more appropriate than the current control, see Fig. 5.

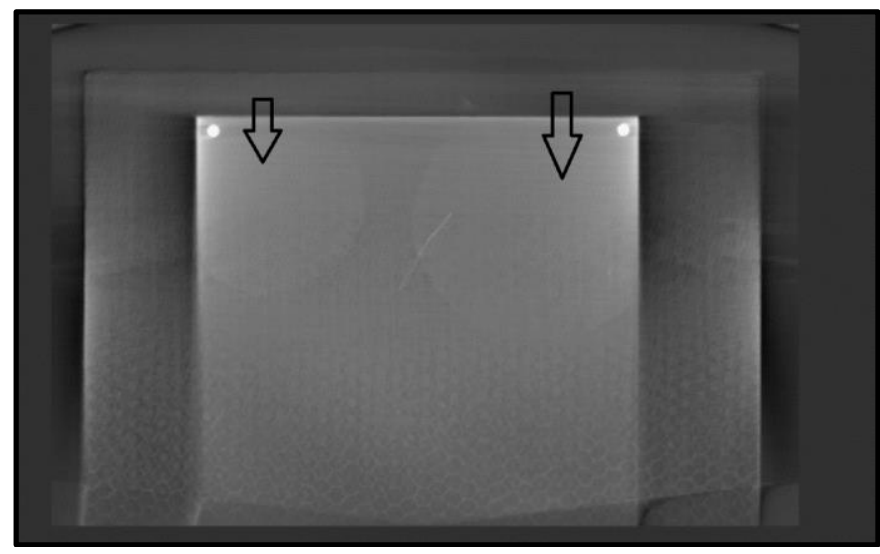

Fig. 5. Cut of the CT model

After adjusting the histogram of the CT model, the differences and the adhesive layer were even more noticeable, see Fig. 6.

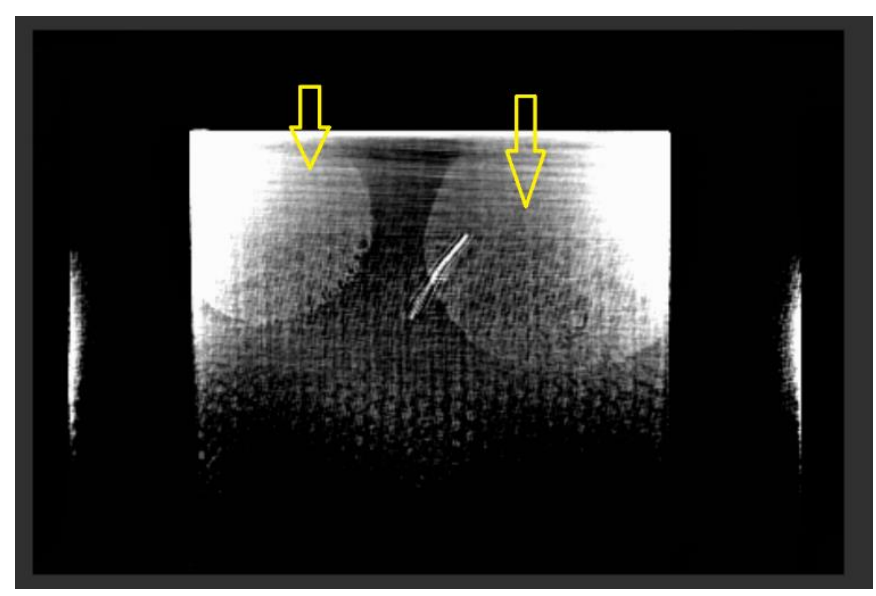

Fig. 6. Cut of the CT model

The design requirement is uniform coverage of the adhesive between the honeycomb and the coating. It can be seen from figures 5 and 6 that the adhesive layer is definitely not uniform over the entire surface of the sandwich composite. The special process, which had been validated so far, and took place under controlled conditions, does not appear to be completely in order. Suddenly, thanks to the use of this non-destructive method, it turns out that even this validated special process is unstable and needs to be further analysed. A mathematical model of the volumetric coverage of the area does not have to be applied here, as by merely visual assessment the coverage can be seen to be about $50 \%$. 


\section{Conclusion}

This article describes the experimental deployment of a non-destructive inspection method using CT models of a sandwich composite (honeycomb) in order to stabilize the validation process and thus increase its credibility because the validated pieces are not destroyed and continue to the customer. We investigated the problem of demanding testing, where the existing destructive testing method gives a large distortion of the results. We achieved excellent results by applying and using new knowledge to check the special process of the construction of a sandwich composite. The CT model provided us not only with information about the whole structure of this material, which is very useful information, but we also found that the layer of adhesive connecting the coating and the honeycomb core is perfectly visible, thus fulfilling the aims of this research.

The results were more than surprising. The customer requires a uniform layer of adhesive in the final product, combining the materials into one unit. Upon closer visual examination of the CT model, it was found that the glue layer covers only about $50 \%$ of the tested sample. Therefore it was not necessary to apply the mathematical model for volume evaluation of coverage, because the requirement was for the area to be covered uniformly. This special process, which was validated and considered to be satisfactory under the current tests, was found not to be. The results showed that the composite has to be subjected to further analysis and corrective measures applied.

The results bring yet another surprising finding. The application of this technology means we are moving from the validation process to verification. For special processes that cannot be tested well enough, such as gluing the honeycomb core and coating, there is no certainty about how the product will turn out until it is destroyed and subjected to a thorough analysis. Thus, the process is validated and this process must take place under certain conditions, typically with a specified humidity and temperature, amount of adhesive, etc., but still there is no certainty as to how the finished product will turn out. Using non-destructive testing in this process makes the entire product visible and it is possible to measure or visually assess it, so the use of this inspection method will surely become a normal process. This means that production still takes place under controlled conditions, but the output is the certainty that the product/material is either OK or NOK, and we have a validated process that can be checked the product. Future research will address the use of more powerful X-ray and CT control system for a variety of materials.

\section{Acknowledgments}

This paper was supported by the project: SGS-2019-008 "Research and Development for Innovation in the Field of Manufacturing Technology - Machining Technology III.

\section{References}

[1] Skrivanova N., Melichar M.: (2019). The Comparison of Destructive and Non-Destructive Forms of Measurement in the Automotive Industry, Proceedings of the 30th DAAAM International Symposium, pp.0995-1002, B. Katalinic (Ed.), Published by DAAAM International, ISBN 978-3-902734- 22-8, ISSN 1726-9679, Vienna, Austria DOI: 10.2507/30th.daaam.proceedings.138

[2] Skrivanova N., Melichar M.: (2019). Comparing the Time Consumption of Destructive and Non-Destructive Forms of Measurement in the Automotive Industry, Proceedings of the 30th DAAAM International Symposium, pp.1003-1007, B. Katalinic (Ed.), Published by DAAAM International, ISBN 978-3-902734-22-8, ISSN 17269679, Vienna, Austria DOI: 10.2507/30th.daaam.proceedings.139

[3] Keran, Z., Mihaljevic M., Horvatic Novak A., Runje B.: (2018). Non Destructive Testing of Forge Welding Joint Errors, Proceedings of the 29th DAAAM International Symposium, ISBN 978-3-902734- 20-4, ISSN 17269679 , Vienna, Austria DOI: 10.2507/29th.daaam.proceedings.024

[4] Horvatic A., Runje B., Butkovic D.: (2016). Influence of Geometrical Magnification on Computed Tomography Dimensional Measurements, Proceedings of the 27th DAAAM International Symposium, ISBN 978-3-90273408-2, ISSN 1726-9679, Vienna, Austria DOI: 10.2507/27th.daaam.proceedings.090

[5] A.Goulas K., Dery S., Dietrich P., R.Johnson G., Grippo A., ChungWang Y., Gross E.: X-ray tomography measurements identify structure-reactivity correlations in catalysts for oxygenates coupling reactions, Catalysis Today, Volume 336, 1 October 2019, Pages 186-192, https://doi.org/10.1016/j.cattod.2018.12.012

[6] Sandwich Structures - an overview | ScienceDirect Topics. ScienceDirect.com | Science, health and medical journals, full text articles and books. [online]. Copyright (C) 2020 Elsevier B.V. or its licensors or contributors. [cit. 08.10.2020]. Dostupné z: https://www.sciencedirect.com/topics/engineering/sandwich-structures

[7] Instytut Metalurgii i Inżynierii Materiałowej Polskiej Akademii Nauk :: Strona główna [online]. Copyright (C) [cit. 08.10.2020]. Dostupné z: http://www.imim.pl/files/archiwum/Vol1_2014/02.pdf

[8] Stekleins, A[ntons]; Gerins, E[riks] \& Kromanis, A[rtis] (2016). Vacuum Gauge Performance Verification System, Proceedings of the 27th DAAAM International Symposium, pp.0607-0614, B. Katalinic (Ed.), Published by DAAAM International, ISBN 978-3-902734-08-2, ISSN 1726-9679, Vienna, Austria DOI: 10.2507/27th.daaam.proceedings.089 